(C) Copyright 2019 Johns Hopkins University Press. All rights reserved. Access to this work was provided by the University of Maryland, Baltimore County (UMBC) ScholarWorks@UMBC digital repository on the Maryland Shared Open Access (MD-SOAR) platform.

Please provide feedback

Please support the ScholarWorks@UMBC repository by emailing scholarworks-group@umbc.edu and telling us what having access to this work means to you and why it's important to you. Thank you. 


\title{
Sexual Communication, Sexual Goals, and Students' Transition to College: Implications for Sexual Assault, Decision-Making, and Risky Behaviors
}

\author{
Kristen P. Lindgren, \\ Assistant Professor of Psychology at the University of Richmond \\ Rebecca L. Schacht, \\ Doctoral candidate at the University of Washington, Seattle \\ David W. Pantalone, and \\ Assistant Professor of Psychology at Suffolk University \\ Jessica A. Blayney \\ Research assistant at the University of Washington; and William H. George is Professor of \\ Psychology at the University of Washington, Seattle
}

\begin{abstract}
A qualitative study was conducted to understand college students' experiences and perceptions of sexual communication and sexual goals, and how they were affected by the transition from high school to college. Participants were heterosexual college students $(N=29)$. Single-sex focus groups were conducted and analyzed for themes. Major themes included gender differences in communication of sexual interest, with men reportedly perceiving more sexualized intentions than women intended to communicate. Gender similarities were observed related to preferring indirect and nonverbal communication and to having more freedom to pursue sexual goals in college. Men focused more intently on casual sex goals, whereas women reported more relationship goals and concerns about reputation.
\end{abstract}

\begin{abstract}
Most research on college student sexuality, including sexual decision-making, risky sexual behavior, and sexual assault, is quantitative. As a result, the voices of college students themselves are underrepresented in the scientific literature, and, as with any field that is dominated by quantitative methodology, it is unclear whether or how much researchers may be imposing their interpretations on the population. In addition, existing research tends to focus on problematic sexual outcomes (e.g., nonconsensual sexual behavior, sexually transmitted infections [STIs], unplanned pregnancy), leaving a gap in our understanding of students' consensual sexual behaviors. This emphasis on quantitative approaches and on problematic outcomes has direct implications for college student development and health care professionals who rely on such findings to develop, provide, and evaluate education, prevention, and intervention programs.
\end{abstract}

Accordingly, this paper uses a qualitative approach to investigate college student sexuality, focusing on the communication of sexual interest and sexual goals about consensual sexual behaviors. It also takes a developmental approach by considering how these issues have been affected, in students' estimation, by the transition from high school to college. Echoing 
researchers on adolescent sexuality (e.g., Impett \& Tolman, 2006; Michels, Kropp, Eyre, \& Halpern-Felsher, 2005; Tolman, 2002; Tolman \& Diamond, 2001), it is our premise that focusing on consensual aspects of sexuality is important in its own right and that doing so also has implications for further understanding, preventing, and intervening in problematic sexual outcomes.

\section{Communication of Sexual Interest}

Although sexual and romantic relationships are of great interest and importance to college students, the communication of such interest can be quite difficult. Indicating one's interest directly may lead to embarrassment, rejection, and/or shame, which can make one reluctant to reveal one's intention too overtly. As a consequence, people engage in behaviors that are indirect, nonverbal, or ambiguous - behaviors that may hint at one's sexual or romantic intentions but that could also be interpreted merely as friendly (Fichten, Tagalakis, Judd, Wright, \& Amsel, 1992; Henningsen, 2004; Metts \& Spitzberg, 1996; Perper \& Weis, 1987).

\section{Unsurprisingly, these behaviors can be difficult to interpret}

There are robust gender differences with respect to perceiving another person's sexual intentions. In particular, college men appear to interpret college women's behavior as more sexual than the women intended, and this difference has been linked to sexual assault and sexual harassment (see recent reviews by Farris, Treat, Viken, \& McFall, 2008; Lindgren, Parkhill, George, \& Hendershot, 2008). Such findings highlight the importance of, and need for, research that identifies the cues linked to misperceptions and sexual assault and, thus, determines how to frame interventions. In addition, this line of research has been primarily quantitative in design. Stimuli usually consist of scenarios scripted by researchers or brief conversations between unacquainted college students, and gender differences have been demonstrated by comparing women's and men's ratings on questionnaires (see Foubert, Garner, \& Thaxter, 2006 , for an exception). Consequently, it is unclear whether, and to what extent, men and women are aware of these differences; whether and how this awareness might impact their behaviors and communication styles; and whether and how well these scenarios and conversations map onto college students' lived experiences. Further, the particular cues that have been investigated have largely been identified by researchers rather than participants.

Qualitative research strategies allow for in-depth exploration of these issues. In addition to lending themselves more naturally to open-ended inquiry and follow-up questions, qualitative strategies can capture complexity and nuances in participants' responses, including hesitations, indirectly expressed frustrations, and when using group formats, concordance (or the lack thereof) among participants (Krueger, 1994). Collectively, previous findings, the limitations of quantitative methods, and the strengths of qualitative methods indicate a need to obtain a clearer picture of the role of sexual communication in college students' sexual behavior. This is particularly important in light of research demonstrating that communication about other aspects of sexuality, such as condom use, abstinence, and consent, has been associated with safer-sex behavior and sexual assault (Foubert et al., 2006; Lefkowitz, Boone, \& Shearer, 2004).

\section{Sexual Goals}

In addition to having differences in both communication and perception of sexual interest, male and female college students may also differ with respect to sexual goals. Although developing intimate relationships and one's sexual identity are central issues for college students in general (see Chickering \& Reisser, 1993; Reisser, 1995), gender differences have been observed. For example, college women have generally been shown to be more interpersonally mature than college men (Foubert, Nixon, Sisson, \& Barnes, 2005; Greeley \& Tinsley, 1988). In addition, 
compared to women, men tend to be more focused on and accepting of casual sex (Oliver \& Hyde, 1993; Ostovich \& Sabini, 2004), want sex more frequently (Sprecher, 2002), and want to have sex earlier in a relationship (Sprecher, Barbee, \& Schwartz, 1995). In contrast, compared to men, women tend to be focused on long-term, committed relationships and prefer that sexual interactions happen as part of a romantic relationship (Bailey, Kirk, Zhu, Dunne, $\&$ Martin, 2000; Oliver \& Hyde). However, these gender differences may be narrowing, with younger women of today becoming more accepting of casual sex as compared to younger women in the past (Oliver \& Hyde).

Research in this area is typically quantitative, and little attention has been given to evaluating college students' first-person reports of their sexual goals. Understanding these processes is important, in part, because sexual goals affect students' dating behavior (Sanderson, Keiter, Miles, \& Yopyk, 2007), particularly sexual risk taking (e.g., Sanderson \& Cantor, 1995). For example, young people whose primary sexual goal is obtaining casual sex may represent different challenges for STI prevention programs than may those whose primary sexual goal is a long-term relationship. Relatedly, sexual goals are linked to students' choices of (familiar vs. unfamiliar) sexual partners: in a sample of fraternity men, having an unfamiliar partner was associated with less direct sexual communication and lower likelihoods of obtaining verbal consent, both of which increase risks for sexual assault perpetration (Foubert et al., 2006).

\section{The Transition from High School to College}

For adolescents, entering college typically brings about more freedom relative to high school and is a time of exploration and expansion. Profound developmental changes that affect romantic and other intimate relationships occur during the transition from high school to college (e.g., Chickering \& Reisser, 1993; Resisser, 1995; Seiffge-Krenke, 2003). College can provide new sources of sexual partners, increased chances for engaging in sexual behavior, and new opportunities to test out different identities and behaviors (e.g., Winefield, \& Harvey, 1996). As noted by Arnett (2000), traditional age college students (i.e., those between the ages of 18 and 22) fit into the developmental period known as emerging adulthood-a period characterized by deliberate change and exploration and increased risk behaviors. In particular, this transition and period can bring increased risk for problematic sexual behaviors. Little published research focuses on college students' reactions to the transition from high school to college and perceived effects on their consensual sexual behaviors and communication. Thus, we sought to bridge this gap by obtaining descriptions of young adults' experience of these changes in their own words.

\section{Rationale}

Given the paucity of qualitative research focused on consensual sexual behavior, this study aimed to deepen our understanding of college students' experiences from the perspective of the college students themselves. In doing so, we aimed to gain a better sense of the extent to which quantitative findings (that are, in essence, taken for granted in the field) did or did not match up to the students' lived experiences. In addition, we sought to understand how the experience of college affected students' sexual communication and sexual goals. Ultimately, we sought to investigate students' reactions and perceptions and to consider their implications for college student development and health. We suggest that understanding college students' sexual goals and communication strategies-i.e., identifying the themes, thoughts, or behavior patterns described by the students themselves-may improve targeting of and/or suggest additional targets for education and intervention for sexual and dating issues. 


\section{Method}

\section{Research Participants and Recruitment}

Twenty-nine undergraduate students (14 men, 15 women) from a large, public university in the Pacific Northwest participated in a study entitled "Sexual Communication Focus Groups." Seventy-three percent identified as Caucasian; the remainder identified as African American (3\%), Asian American (14\%), or biracial (10\%). The sample's demographics were equivalent to the university's demographics, with the exception of the overrepresentation of Caucasians (who represent approximately 63\% of the student body) and the underrepresentation of Asian Americans (who represent approximately $26 \%$ of the student body). All identified as heterosexual. Seventy-six percent of the sample reported being in their first year of college. Students were between the ages of 18 and 22 years $(M=18.8, S D=.9)$.

Focus groups were held during winter quarter. Thus, most participants had experienced only 3 months of college before they joined the study. All participants were recruited from the Psychology Department's Subject Pool and were given extra course credit for their involvement in the study. Participants were instructed not to sign up for a focus group with friends and/or acquaintances. Procedures were approved by the university's Internal Review Board.

\section{Procedures}

There were four groups in the study: two all male groups and two all female groups. Each session lasted 90 minutes and was audio taped. The focus group portion lasted about 70 minutes. The remaining time was used to administer written informed consent documents and a brief demographic questionnaire, review group rules for the discussion, and conduct an icebreaker exercise. All focus groups were led by a gender-matched graduate student and undergraduate research assistant pair. Each focus group comprised 6 to 8 same-sex participants. Facilitators' training included readings from the focus group literature (e.g., Krueger, 1994; Morgan; 1988), training in active listening skills, and practice role plays.

Ground rules, which were intended to maximize privacy and confidentiality, were reviewed with all participants. Participants were instructed: (a) not to discuss specific personal sexual experiences but to discuss how, in general, individuals their age talk about sex; (b) never to use names; (c) to talk one at a time; and (d) not to talk about the session after it was completed. No names were transcribed, real or fictitious.

As recommended by Morgan (1988), groups began with an icebreaker exercise to serve as a general introduction to the topic, model for the student our reliance on their expertise and experiences, and acclimate them to the group context. Participants watched three brief clips from a teen movie (She's All That) that included examples of sexual communication and detecting sexual intentions. Participants then discussed what aspects of the scenes presented were realistic versus not realistic. One clip was intended to be relatively realistic (i.e., the male character asked a female character out on a date), whereas the others were not (i.e., a male character helped his female romantic interest by having members of his sports team clean her house). The clips took 5 minutes to watch and discussion lasted approximately 10 minutes. Focus group discussion began immediately after the ice breaker exercise. The first question was, "How do you think sexual communication has changed over time, meaning from high school to now?" The order of the remaining questions was left to the moderator's judgment in the interest of maintaining a natural conversational flow.

Questions were intended to clarify particular aspects of sexual communication, including gender differences, verbal versus nonverbal communication, sending versus receiving messages, communication strategies for indicating comfort or lack of comfort with sexual 
activities, communication strategies for short-term and long-term relationships, and the role of alcohol. Information on the latter topic is reported separately (Lindgren, Pantalone, Lewis, \& George, 2009). Focus group questions were drawn from the literature on sexuality, sexual intentions, and dating, which spans psychology, communication, and sexuality fields (e.g., Fichten et al., 1992; Lindgren et al., 2008; Metts \& Spitzberg, 1996; Perper \& Weiss; 1987; Tolman, 2002).

Participants were asked to explain, elaborate on, or dispute any comments that were made during the session in order to allow participants to clarify their responses and, thus, enhance the breadth and depth of the group discussions.

All focus groups were transcribed fully. Transcripts were structured so that each paragraph represented an individual speaker. To promote consistency and accuracy, transcripts were double-checked for accuracy by independent research assistants. The final transcript was accepted unanimously by researchers. Data collection and analysis was guided by the theory and methods of content analysis (Krippendorf, 2004), a standard qualitative paradigm in which the voices of the participants are placed at the center of the analysis. The goal of content analysis is to add to the collective understanding of a given phenomenon by classifying a large amount of relevant text into thematic categories that represent the central ideas present in the data.

Content analysis involves a close reading of the text to determine relevant codes, categories, and themes. No codes, categories, or themes were specified a priori. Two investigators, who also served as the senior focus group facilitators, read the transcripts multiple times.

Independently, both highlighted and coded relevant text in all transcripts and gave the code a descriptive label; codes could represent either explicit or inferred communication

(Krippendorf, 2004). Then, the iterative process of reading through each of the transcripts line by line and coding, categorizing, discussing, and refining ideas began. Codes were given to selected areas of text, indicating content (e.g., "relationship goals change from high school to college" and "relationships are work"), the gender of the speaker, and the gender about which the comment was made (e.g., women's views of men's behaviors, men's view of their own behavior). Multiple codes, understood together, were grouped into areas of relative agreement (i.e., men and women agree about men's behavior X) and disagreement (e.g., women see themselves as almost exclusively interested in romantic relationships and men want both casual sex and romantic relationships). These themes were aggregated to comprise the theme areas listed below.

The use of various forms of triangulation — multiple sources of data (i.e., multiple participants, multiple focus groups), multiple readings, multiple coders, and the iterative process of consensual agreement-enhanced the verification and validity of the analysis (Patton, 2002). Using the final coded version of the transcripts, representative quotes were chosen and are reproduced here.

\section{Results}

\section{Sexual Interest Communication and Perception}

Participants gave examples of how sexual interest and disinterest were communicated. Men and women agreed in some respects. For example, sexual conversation, talking about values, agreeing to go somewhere private, and body language such as eye contact and "accidental" touching were cited as expressions of sexual interest. Disinterest was expressed through body language, such as walking away from a prospective partner, pulling away physically, avoiding eye contact, distancing oneself physically from the person, and crossing one's arms to avoid contact. Lying could also be used to express disinterest (e.g., claiming to have a boyfriend or having to make an important call). Indirect communication was typically used before direct 
communication to express disinterest. Verbal communication was described as a last resort, used only if the other party did not pick up on repeated, indirect cues of disinterest:

There's almost a point where you just have to stop and say, "Okay, I don't like you that way!" You're forced to become verbal with the person when shying away. And [expressing] yourself with body language is not enough. You actually have to say it to the person, that it is not the right thing to do. (female participant)

Gender differences in sexual communication and perception were also found. Women reported using indirect communication rather than direct communication to protect men's feelings and linked their use of indirect strategies to concerns about men's feelings: "Women are trying to be nice and not blunt because they don't want to hurt people's feelings" (female participant). Women also reported that men often did not pick up on sexual disinterest cues: "[Women] expect men will be able to pick up on the things they are so clearly sending out ... but [men] don't always pick up that you're not reciprocating" (female participant). Men reported that they sometimes picked up on, and disregarded, women's behavioral cues that indicated a lack of interest. They also reported some reliance on different aspects of women's comportment, namely women's style of dress, to assess women's interest in sex:

[A woman] pretty much knows what she's anticipating based on the way she dresses or at least they have a clue. Because if she's wearing jeans and a regular sweatshirt, then you are like, "Ah man, I'm not going to get anything!" And then you see like a girl who wears a hoochie top and you're like, "All right!" (male participant)

I think if she dressed up, it doesn't really matter if it's slutty or not ... if she dressed up, then it looks like she's interested in you, trying to, ya know, look good for you. (male participant)

In contrast, women did not cite style of dress as a method of communicating sexual interest. Both sexes agreed that men typically saw more sexual intent than women communicated. Men characterized themselves as being more direct than women when expressing sexual interest.

\section{Sexual Goals}

Women's reports suggested that their sexual goals were less flexible than were the men's. Women characterized themselves typically as knowing "how far" they would allow a sexual interaction to go in advance. In addition, women wanted men to be interested in them for "who they were," and not just as sexual objects. Men agreed with the idea that women had more fixed sexual boundaries and noted that, in their experience, some women would not have sex outside of a committed relationship. They characterized women as more likely to seek longterm relationships than casual sex. In contrast, men were characterized by both sexes as always wanting sex, regardless of relationship status. Thus, women saw themselves as sexual gatekeepers, that is, as responsible for deciding whether and how much sexual interaction would occur. Often this decision was made in advance:

You need to tell your partner way before anything [sexual] is gonna happen—like, as soon you start going out, [tell him] what your limits are, where you draw the line because, if you don't say anything soon and you wait too long, the little lines aren't going to be there anymore because [your partner] won't know and you'll just be letting [him] push the lines farther and farther away. (female participant)

I think the guy kind of has an idea if she is the kind of girl that is down for it, or is sexually active or not. (male participant)

Men described both casual sex and long-term relationships in terms of work. They noted that obtaining these goals required effort on a man's part. Casual sex was characterized as a 
challenge or a conquest that was enjoyable, whereas long-term relationships were characterized as work that was more onerous and less exciting than the pursuit of more casual relationships:

Sex isn't such a challenge [in relationships]. It's not a pursuit as much as in a long term relationship versus short term. ... Us guys, we love challenges. In [the] short term ... you have a challenge there. You're trying to get to an initial goal. If you don't meet that goal then, ya know, you've pretty much failed or you try again later. But in a long term relationship, there's no goal. You're just together. (male participant)

Short term is a challenge: "I want this. Whatever I gotta do to get this!" (male participant)

Men reported manipulating situations to increase the likelihood of having sex. Strategies included giving women alcohol, trying to be alone with a woman, and using "pickup lines."

Men also reported that, typically, women were either casual sex partners or prospects for longterm relationship partners. Rarely did a casual sex encounter result in a long-term relationship:

For the first night you hook up with the person, I haven't seen ... I barely ever see relationships after that ... There are rare cases where there's a progression, but there's a lot more cases where a relationship forms if they don't [have sex on the first date]. (male participant)

\section{Developmental Changes in Sexuality: High School vs. College}

Both men and women discussed changes that occurred between high school and college. Structural differences, such as increased physical freedom and privacy in college relative to high school, were cited as increasing accessibility to sex:

It's so much easier [to be sexually active in college]. Your inhibitions are lowered, you're older, and everyone else is doing it. I think that it changes from high school, because in high school you can't really have sex as easily because your parents are in the house or you don't own a car whereas [in college] most people have their own place or apartment to do it in. (female participant)

Well, the fact that a lot of people don't live at home [allows more access to sex in college than in high school], there's a lot more freedom and so it's a lot easier to start things off. (male participant)

Both sexes reported that these changes, in addition to increased sexual experience by the time they reach college, resulted in more openness and freedom regarding sexuality. Women reported that sexual conversations were more acceptable in college relative to high school and that they had become less concerned that talking about sex implied promiscuity:

In my experience of listening to people, they are much more unembarrassed and unashamed [when talking about sex in college]. They just view themselves as much more adult, and they expect other people to rise to that level and deal with it in the same way. (female participant)

Women reported a shift in social influences on their sexual behavior. In high school, external influences such as parents, religion, or friends were emphasized, whereas women's own wishes were cited as more influential in determining their sexual behavior in college. Casual sex was characterized by both sexes as more acceptable in college relative to high school:

In high school, even if you yourself might think it is okay [to have sex] ... there is someone resisting your opinions ... like, you are always thinking, "Well, $I$ think it's right but do my parents think it's wrong? So maybe I should think it's wrong." (female participant) 
A lot of girls in high school don't want their reputation hurt and same with the guys ... In college, there's not as much gossiping. A girl or a guy can do what they want and not worry about hurting their reputation. Sex is more expected in college, I think. (male participant)

The shift toward increased sexual autonomy was seen by women as occurring secondary to their developing a stronger "sense of self" as they grew older:

In college, it's like you are on your own, and it is about you and you don't care and other people are not keeping tabs on your relationships. I think it's about your own personal desires and not about your group of friends and your clique's desires. (female participant)

Women characterized men as more mature in college as well, stating that men were less afraid of women, more respectful, and more subtle in their pursuit of women than in high school. Men did not highlight such changes in themselves or remark about any similar changes in women.

Sexual goals also evolved with age. As sexual experience increased, motivation for both sexes to have sex simply to gain experience appeared to decrease. Women reported that, in college, both sexes waited longer to have sex and that men were more interested in getting to know women before having sex with them than in high school. They also reported perceptions that both men's and women's interest in long-term relationships increased in college relative to high school, and men's and women's interest in casual sex decreased:

I think that as we're getting older, or going from high school to college, that relationships are more on people's minds. They are looking towards marriage or a long term commitment. (female participant)

I've just seen how much more seriously people take relationships [in college].... They're not in it just for the sexual experience. Dating is different in college in that people get married more often. (female participant)

Like women, men also characterized themselves as more interested in long-term relationships relative to high school, but contrary to women's perceptions, they also characterized themselves as continuing to be interested in casual sex in college:

In college, [dating is] kind of more meaningful, in that you're trying to genuinely get to know someone rather than just promising them stuff just to hook up with them. (male participant)

Guys will think of ways to get girls into their room [describes several techniques] ... usually when the girl [does go] up to his room, they do hook up. (male participant)

\section{Discussion}

The results indicate gender similarities and differences in sexual interest communication and perception, sexual goals, and developmental changes in sexual behavior from high school to college. Congruent with findings from the (mostly quantitative) literature, we found that indirect approaches were used more often and were preferred to direct, overt approaches to communicate sexual intent. Also consistent among men and women's groups was the idea that men typically perceived more sexual intent than women were trying to communicate. Unique to the women's groups was that women reported favoring indirect communication to express disinterest, which was described as a strategy to avoid hurting men's feelings, but that women would eventually escalate to direct communication if men did not respond to indirect communication. Unique to the men's groups was their focus on women's self-presentation, in particular, a woman's style of dress, as a cue for a woman's sexual interest-i.e., a woman 
who is dressed up is a woman who is sexually interested and available. In general, these findings are fairly consistent with qualitative research with college fraternity men by Foubert and colleagues (2006), which indicated that men not only preferred indirect sexual communication strategies but that they were averse to verbal communication related to sexual consent due to concerns about being rejected.

With regard to sexual goals, gender differences, rather than similarities, were most apparent. The men's and women's reports from these focus groups reflected more traditional attitudes. In particular, women emphasized their interest in long-term relationships and their roles as sexual gatekeepers, whereas men emphasized casual sex and the (exciting) challenge involved in obtaining it, as well as their roles as sexual initiators. This finding was somewhat surprising given research suggesting that the sexual double standard is less robust today than in the past (Miller, Perlman, \& Brehm, 2007; Regan, 2003) and the location of the university campus from which we recruited student participants (i.e., a politically liberal, socially progressive Pacific Northwestern city). Many students from the university do come from more rural, politically conservative regions of the state, which may account for the more traditional nature of their views. It is also possible that self-presentation concerns (see "Limitations" below) contributed to participants expressing more traditional views. Finally, it is also possible that gender differences in sexual goals may reflect consistent, robust gender differences in the development of intimate relationships that have been found in college students (e.g., Bogle, 2008; Foubert et al., 2005; Greeley \& Tinsley, 1988) and incorporated into theories of college student development (e.g., Chickering \& Reisser, 1993; Reisser, 1995).

Finally, similarities and differences characterized men and women's reactions to the transition to college. In particular, themes related to increased physical freedom, privacy, and openness were evident and linked to being more able to pursue and engage in sexual activity. Men and women reported that this appeared to be particularly important in terms of their ability to be sexual and to maintain a "good" reputation. Interestingly, women reported changes in their own and men's maturity and linked that to changes in their own and men's sexual goals, but men did not report such changes. Such findings resonate with theories of college student development (e.g., Chickering \& Reisser's, 1993, "seven vectors"), which identify multiple dimensions of identity that change and develop throughout a student's college experience. In particular, themes from the present study echoed Chickering and Reisser's vectors of managing emotions (particularly related to sex and aggression), moving through autonomy toward interdependence, developing mature interpersonal relationships, developing purpose, and developing integrity. The majority of student participants were early in their college career and were in the early stages of 'working through' this transition. Although peers remained of central importance and were highly influential, student participants were also grappling with the increased freedom, privacy, autonomy, which can allow for increasing independence and agency. In addition, these findings also are consistent with Bogle's (2008) in-depth qualitative study of the "hook-up" culture on college campuses. For example, Bogle highlighted the paradox of (a) college students' perceptions of increased privacy and autonomy with regard to sexual behavior and (b) their considerable attention to and discussion of other students' behavior and the perceived (sexual) norms of their campus, which ultimately results in (some) constraints on their behavior.

\section{College Student Development and Health Implications}

Our findings have implications for research on and interventions with college students in terms of sexual assault. Women reported that they typically express sexual disinterest indirectly, and men reported that they typically perceive more sexual interest than women feel. These findings replicate past work indicating that men perceive, expect, and desire more sex than do women and do so earlier in a romantic relationship (e.g., Bartoli \& Clark, 2006; Farris et al., 2008; 
Lindgren et al., 2008; Sprecher, 2002; Sprecher et al., 1995). Notably, these findings imply that men may have difficulty reading women's expressions of sexual interest, which, thus, could be a precursor to sexual assault.

Moreover, both men and women expressed preferences for indirect and nonverbal forms of sexual communication. As discussed earlier, direct, verbal communication seemed to be viewed as a "last resort," which is particularly concerning and echoes work by Foubert and colleagues (2006). These results suggest that there are a myriad of ways in which the sexual communication between partners may be ambiguous, unclear, confusing, misunderstood, and potentially pave the way for a nonconsensual encounter. Moreover, despite the increasingly sexual nature of media content that saturates adolescents and emerging adults, college students still indicate considerable reluctance to communicate directly and verbally with their partners.

Ultimately, these results underscore the importance of Foubert et al.'s (2006) recommendations for sexual assault prevention - and we suggest sexual and sexuality education-programs to (a) develop methods to teach college men and women to communicate verbally and directly about sexual preferences, desires, and consent and (b) identify strategies that will increase their tolerance for and comfort with doing so. It may be possible to teach college students direct communication skills as means of enhancing sexual encounters and increasing pleasure and desire. Implicit in this recommendation is the notion of well-constructed, developmentally appropriate, and noncondescending programming that not only identifies the importance of sexual communication for minimizing risk and harm to oneself and one's partner but also the possibility that talking about sex with one's partner can be sexy and fun. Further, we suggest that is it critical to provide programming that also highlights (a) that there are gender-based differences in perceptions in sexual intentions and (b) the ways in which these differences can be exacerbated by alcohol (Farris et al., 2008; Lindgren et al., 2008, Loiselle \& Fuqua, 2007). Overall, these findings underscore the importance of programming that identifies direct communication as both a protective behavioral strategy and a source of pleasure and enhancement.

These findings also have implications for unintended pregnancies and HIV/STI prevention. In a meta-analysis, Sheeran, Abraham, and Orbell (1999) found that the strongest predictor of condom use was sexual communication. Our participants' discomfort with direct sexual communication suggests that college student health and wellness promotion programs may benefit from an emphasis on direct communication and, in particular, on individualized elicitation of pros and cons as well as skill building and enhancement through rehearsal or role plays with peers. In addition, addressing students' sexual goals as part of STI interventions may enhance audience fit, thereby enhancing efficacy.

\section{Limitations}

Limitations of this work should be noted. First, the generalizability of these findings is limited by the sample, which was relatively small, predominantly European-American, and drawn from a single, large public university in an urban setting. The sample was heterosexual, and these results may be less relevant to students who identify as lesbian, gay, bisexual, or transgender, or those who are questioning their sexual orientation. Second, self-presentation may have influenced the nature and content of participants' comments. The focus group method gives participants a voice, allows discussion, and provides a sense of agreement/disagreement among participants. It is also a public sphere-one in which a majority or more vocal members could silence or influence others and/or in which a minority could choose to remain silent and suppress disagreement to maintain consensus (e.g., Morgan, 1988). As a result, students might have voiced more gender stereotypical responses (e.g., women presenting themselves as more demure/chaste; men presenting themselves as more macho/sexual) and/or have withheld more gender atypical responses (e.g., women presenting themselves as more sexual; men presenting 
themselves as more relational or chaste) than they would have in private. We took steps to minimize this possibility by having an undergraduate research assistant co-lead the groups and asking students to sign up for groups only with people they did not know. Self-presentation may also be a significant factor in other social situations (e.g., classes, parties, work) that these students experience, and their responses may be indicative of how they present themselves in other social settings.

Also related to focus group methods are concerns about the extent to which participants' responses, which stem from an interaction in a group setting, would or would not mirror the individuals' behavior. This is an inherent limitation of focus groups, and it has been argued extensively elsewhere that this limitation is offset by the opportunity for researchers to learn about and explore a topic with a group relatively quickly and cost-effectively (see Morgan, 1988). In addition, our ground rules included instructions for participants to speak not about their own individual experiences but about behavior of students in general. These rules stemmed from the institutional review board's concerns about protecting students' privacy and confidentiality. These ground rules may have created distance between participants' private experiences and their public discourse, which may in turn have increased generalization and, possibly, stereotyping. Finally, based on the research design used, we were unable to present our results to the student participants to elicit their feedback about our conclusions. As a result, we lack in-group feedback about our interpretations of the data.

\section{Conclusions}

We conducted a qualitative study to allow college students to describe their sexuality in their own voices. We found relatively stable gender differences in sexual goals and communication. Differences in men and women's sexual behavior continue from high school into college. These differences have important implications for student development and health promotion curricula currently implemented on a variety of college campuses

\section{Acknowledgments}

Manuscript preparation was supported by T32 AA007455 (PI: Larimer) and K99 AA017669 (PI: Lindgren).

\section{References}

Arnett JJ. Emerging adulthood: A theory of development from the late teens through the twenties. American Psychologist 2000;55:469-480. [PubMed: 10842426]

Bailey JM, Kirk JM, Zhu G, Dunne MP, Martin NG. Do individual differences in sociosexuality represent different genetic or environmentally contingent strategies? Evidence from the Australian Twin Registry. Journal of Personality and Social Psychology 2000;78:537-545. [PubMed: 10743879]

Bartoli AM, Clark DM. The dating game: Similarities and differences in dating scripts among college students. Sexuality \& Culture 2006;10:54-80.

Bogle, KA. Hooking up: Sex, dating, and relationships on campus. New York: New York University Press; 2008.

Chickering, AW.; Reisser, L. Education and identity. 2. San Francisco: Jossey-Bass; 1993.

Farris C, Treat TA, Viken RJ, McFall RM. Sexual coercion and the misperception of sexual intent. Clinical Psychological Review 2008;28:48-66.

Fichten CS, Tagalakis V, Judd D, Wright J, Amsel R. Verbal and nonverbal communication cues in daily conversations and dating. Journal of Social Psychology 1992;132:751-769.

Foubert JD, Garner DN, Thaxter PJ. An exploration of fraternity culture: Implications for programs to address alcohol-related sexual assault. College Student Journal 2006;40:361-373. 
Foubert JD, Nixon ML, Sisson VS, Barners AC. A longitudinal study of Chickering and Reisser's vectors: Exploring gender differences and implications for refining the theory. Journal of College Student Development 2005;46:461-471.

Greeley AT, Tinsely HEA. Autonomy and intimacy development in college students: Sex differences and predictors. Journal of College Student Development 1988;29:512-520.

Henningsen DD. Flirting with meaning: An examination of miscommunication in flirting interactions. Sex Roles 2004;50:481-489.

Impett EA, Tolman DL. Adolescent girls' sexual experiences and sexual satisfaction. Journal of Adolescent Research 2006;6:628-646.

Krippendorf, K. Content analysis: An introduction to its methodology. 2. Thousand Oaks, CA: Sage; 2004.

Krueger, RA. Focus groups: A practical guide for applied research. 2. Newbury Park, CA: Sage; 1994.

Lefkowitz ES, Boone TL, Shearer CL. Communication with best friends about sex-related topics during emerging adulthood. Journal of Youth and Adolescence 2004;33:339-351.

Lindgren KP, Panalone DW, Lewis MA, George WH. A qualitative analysis of college students' perceptions about alcohol and casual sexual behavior: Alcohol leads to sex. Journal of Drug Education. 2009 In press.

Lindgren KP, Parkhill MR, George WH, Hendershot CS. Gender differences in perceptions of sexual intent: A qualitative review and integration. Psychology of Women Quarterly 2008;32:423-439. [PubMed: 19763282]

Loiselle M, Fuqua WR. Alcohol's effect on women's risk detection in a date-rape vinette. Journal of American College Health 2007;55:261-66. [PubMed: 17396398]

Metts, S.; Spitzberg, BH. Sexual communication in interpersonal contexts: A script-based approach. In: Burleson, BR., editor. Communication yearbook. Vol. 19. Thousand Oaks, CA: Sage; 1996. p. 49-92.

Michels TM, Kropp RY, Eyre SL, Halpern-Felsher BL. Initiating sexual experiences: How do young adolescents make decisions regarding early sexual activity? Journal of Research on Adolescence 2005;15:583-607.

Miller, RS.; Perlman, D.; Brehm, SS. Intimate relationships. 4. Boston: McGraw-Hill; 2007.

Morgan, DL. Focus groups as qualitative research: Qualitative Research Methods. Vol. 16. Newbury Park, CA: Sage; 1988.

Oliver MB, Hyde JS. Gender differences in sexuality: A meta-analysis. Psychological Bulletin 1993;114:29-51. [PubMed: 8346327]

Ostovich JM, Sabini J. How are sociosexuality, sex drive, and lifetime number of sexual partners related? Personality and Social Psychology Bulletin 2004;30:1255-1266. [PubMed: 15466599]

Patton, MQ. Qualitative research and evaluation methods. 3. Thousand Oaks, CA: Sage; 2002.

Perper T, Weis DL. Proceptive and rejective strategies of U.S. and Canadian college women. Journal of Sex Research 1987;23:455-480.

Regan, P. The mating game: A primer on love, sex, and marriage. Thousand Oaks, CA: Sage; 2003.

Reisser L. Revisiting the seven vectors. Journal of College Student Development 1995;36:505-512.

Sanderson CA, Cantor N. Social dating goals in late adolescence: Implications for safer sex activity. Journal of Personality and Social Psychology 1995;68:1121-1134. [PubMed: 7608858]

Sanderson CA, Keiter EJ, Miles MG, Yopyk DJA. The association between intimacy goals and plans for initiating dating relationships. Personal Relationships 2007;14:225-243.

Seiffge-Krenke I. Testing theories of romantic development from adolescence to young adulthood: Evidence of a developmental sequence. International Journal of Behavioral Development 2003;27:519-531.

Sheeran P, Abraham C, Orbell S. Psychosocial correlates of heterosexual condom use: A meta-analysis. Psychological Bulletin 1999;125:90-132. [PubMed: 9990846]

Sprecher S. Sexual satisfaction in premarital relationships: Associations with satisfaction, love, commitment, and stability. Journal of Sex Research 2002;39:190-196. [PubMed: 12476266]

Sprecher S, Barbee A, Schwartz P. "Was it good for you, too?": Gender differences in first sexual intercourse experiences. Journal of Sex Research 1995;32:3-15. 
Tolman, DL. Dilemmas of desire: Teenage girls talk about sexuality. Cambridge, MA: Harvard University Press; 2002.

Tolman D, Diamond L. Desegregating sexuality research: Cultural and biological perspectives on gender and desire. Annual Review of Sex Research 2001;12:33-74.

Winefield HR, Harvey EJ. Psychological maturity in early adulthood: Relationships between social development and identity. The Journal of Genetic Psychology 1996;157:93-103. 